\title{
Evaluation of a fecal immunochemistry test pric
to colonoscopy for outpatients with various indications
}

\author{
Andrew Szilagyi' \\ Xiaoqing $\mathrm{Xue}^{2}$ \\ 'Division of Gastroenterology, \\ ${ }^{2}$ Division of Emergency Medicine, \\ Jewish General Hospital, McGill \\ University School of Medicine, \\ Montreal, Quebec, Canada
}

\author{
This article was published in the following Dove Press journal: \\ Clinical and Experimental Gastroenterology \\ 10 November 2017 \\ Number of times this article has been viewed
}

Correspondence: Andrew Szilagyi Division of Gastroenterology, Jewish General Hospital, McGill University School of Medicine, 3755 Cote Sreet, Catherine Road, Room EI I0, Montreal, Quebec H3T IE2, Canada

$\mathrm{Tel}+\mathrm{I} 5|43408| 44$

Fax + I 5143408282

Email aszilagy@jgh.mcgill.ca
Background: Stool tests can predict advanced neoplasms prior to colonoscopy. Results of immunochemical stool tests to predict findings at colonoscopy for various indications are less often reported. We compared pre-colonoscopy stool tests with findings in patients undergoing colonoscopy for different indications.

Patients and methods: Charts of patients undergoing elective or semi-urgent colonoscopy were reviewed. Comparison of adenoma detection rates and pathological findings was made between prescreened and non-prescreened, and between stool-positive and stool-negative cases. Demographics, quality of colonoscopy, and pathological findings were recorded. Odds ratios (ORs) and 95\% confidence intervals (CIs) were assessed. Statistical significance was accepted at $p \leq 0.05$.

Results: Charts of 325 patients were reviewed. Among them, stool tests were done on 144 patients: 114 were negative and 30 were positive. Findings were similar in the pretest and nonpretest groups. Detection of advanced adenomas per patient was higher in the stool-positive group compared to the stool-negative group $(23.4 \%$ vs $3.5 \%, p=0.0016$, OR $=7.6[95 \% \mathrm{CI}$ : 2-29.3]). Five advanced adenomas (without high-grade dysplasia or adenocarcinoma) and several cases of multiple adenomas were missed in the negative group. Sensitivity and specificity for advanced polyps was $63.6 \%$ and $82.7 \%$, respectively. The negative predictive value was $96.5 \%$. Male gender was independently predictive of any adenoma.

Conclusion: The stool immunochemical test best predicted advanced neoplasms and had a high negative predictive value in this small cohort. Whether this test can be applied to determine the need for colonoscopy in groups other than average risk would require more studies.

Keywords: fecal, blood, risks, colonoscopy, outcome

\section{Introduction}

Colorectal cancer (CRC) is the third most common cancer in the Western world and is the second most deadly cancer. ${ }^{1}$ However, early cancer detection has now been shown to reduce mortality. ${ }^{2,3}$ In addition, because most CRCs are initially related to benign colonic adenomas, removal of tubular (TA), tubulovillous (TVA), and serrated adenomas could reduce $\mathrm{CRC}$ incidence. As a result, most Western nations have undertaken population screening programs. There are different programs used to perform colonoscopy screening. ${ }^{4}$ Among these, the fecal immunochemistry test (FIT) has been shown to have both high sensitivity and specificity in identifying CRC and advanced polyps throughout the colon ${ }^{5}$ in a population with average risk for colon cancer. A meta-analysis of 19 such studies showed that the pooled sensitivity, specificity, positive likelihood ratio, and negative likelihood ratio of a single FIT for cancer were 0.79 (95\% 
CI: 0.69-0.86), 0.94 (95\% CI: 0.92-0.95), 13.10 (95\% CI: $10.49-16.35$ ), and 0.23 (95\% CI: $0.15-0.33)$, respectively. ${ }^{6}$ In this meta-analysis, the sensitivity and specificity of a single FIT result were similar to those of multiple samples, suggesting this test is quite accurate. Although generally evaluated in homogenous average-risk populations for the purpose of screening, the role of FIT testing in a clinically heterogeneous group of patients undergoing colonoscopy for a variety of reasons has been less reported. This may be relevant in addressing whether the FIT may also be useful in cases with higher risks for colonic neoplasms. ${ }^{7,8}$

In the Quebec region, the FIT test has become universally available in the last few years. It is being incorporated in a general screening program in the province; however, current decisions regarding elective colonoscopies are based on accepted clinical risk categories. ${ }^{7,8}$ The general availability of the test allowed an opportunity to further triage cases for more rapid access to colonoscopy, thus reducing wait times. In addition, comparison of colonoscopy outcomes with a single one-time FIT test could reinforce the test's value. The aims of this retrospective study were to 1) compare the outcome of colonoscopy in FIT-negative and FIT-positive patients undergoing colonoscopy for a variety of indications and 2) compare the performance in FIT prescreened patients with standard colonoscopy. In the latter case, the non-prescreened group was used for standard quality assurance in case the FIT alters risks and modifies performance.

\section{Patients and methods}

The computerized charts of patients who underwent elective or semi-urgent colonoscopy at the Jewish General Hospital in Montreal between January 4, 2015 and September 30, 2016 were reviewed. Urgent and emergency colonoscopies were excluded due to the multiple staff and gastroenterology fellows who performed the colonoscopies. Source of data was the EndoVault ${ }^{\circledR}$ program which has been in use for more than 2.5 years (Endosoft LLC, Schenectady, NY, USA). The protocol was approved by the Research and Review committee of the Jewish General Hospital. As this study was a retrospective chart review using deidentified patient data, informed consent was not required.

In the gastroenterology clinics, patients are given standard written instructions on preparations for colonoscopy. They are told to take either powdered magnesium sulfate (PicoSalax ${ }^{\circledR}$; Ferring Inc., Ontario, Canada) or Peglyte ${ }^{\circledR}$ (PendoPharm Inc., Montreal, Canada) (4 L split doses the day before and morning of colonoscopy).

Charts were initially retrieved by an independent observer in charge of bookings at the gastroenterology laboratory
(WGK). After initial review, the charts were again reviewed in detail by one of the authors (AS). The following data were retrieved: identification, date of procedure, age, gender, and reasons for colonoscopy. Pre-colonoscopy risk factors such as family history, previous colonoscopy findings, and any symptoms were recorded and were based on history from the patient or from the referring physician. In the case of iron deficiency, some patients had obvious decrease in ferritin with or without anemia, while in others history from the referring physician was available.

Quality markers of colonoscopy recorded were extent of exam (cecal intubation was necessary for inclusion), effectiveness of cleansing preparation, which is part of the computerized recording of colonoscopies (the Aronchick system is incorporated into the computer program), ${ }^{9,10}$ withdrawal time, and findings on endoscopy and pathology.

Pathology reports were used to retrieve information about histology and size of polyps. Polyps were defined according to the World Health Organization classification of tumors. In this classification, adenomas are classified as TA, villous adenoma, TVA, and serrated adenoma. ${ }^{11}$ Presence of high grade dysplasia and then limited intramucosal and invasive adenocarcinoma (invasion beyond the muscularis mucosa) is reported. Hyperplastic polyps (HP), sessile serrated adenomas (SSA), and several other findings were tabulated for completeness.

Advanced adenomas included tumors $10 \mathrm{~mm}$ or more in diameter, villous adenoma, adenoma with high-grade dysplasia (HGD), or invasive adenocarcinoma. ${ }^{12}$ In cases of multiple adenomas, the largest polyp per patient was considered. However, adenoma per colonoscopy rate was not included.

The adenoma detection rate (ADR $\geq 1$, adenoma of any size per patient excluding serrated adenomas and HP) was calculated. ${ }^{13,14}$ Strictly defined, the ADR refers to adenomas detected in average-risk patients $>50$ years. However, because the purpose was to evaluate the performance of FIT in a heterogenous population, the groups were divided based on the presence or absence of symptoms. In this paradigm, the term "screening" includes patients stratified by current risk classification (average risk, family history, and previous colonoscopy findings). Indications for symptoms included rectal bleeding, iron deficiency (with or without anemia), abdominal pain, change in bowel pattern, diarrhea (but not chronic constipation), or weight loss. Therefore, the overall "ADR" refers to all detected adenomatous neoplasms.

Starting in July 2015, most patients referred for colonoscopy were also asked to do an immunological stool FIT test, the results of which were also retrieved from the charts. This 
stool test was readily available for routine use in our hospital. The rationale was to attempt to triage more patients, since waiting times here may be excessive.

The kit was usually retrieved by the patient at the hospital test center after the visit at which time the colonoscopy was scheduled and returned on completion. Written instructions were provided with the kits. A single sample is drawn with a small tube inserted into the stool, and then collected onto a paper tissue before it contacts water. The sample is then placed into a tube with a small amount of preservative buffer and sent back to the hospital. The stool FIT test is sent to the central government laboratory at the University of Sherbrooke, Quebec City. The analysis kit use a OC-Sensor (Polymedco OC-Auto ${ }^{\circledR}$; Polymedco CDP, LLC, Cortland Manor, NY, USA) and uses $175 \mathrm{ng}$ of hemoglobin $(\mathrm{Hgb}) / \mathrm{mL}$ of buffer as per manufacturer's cutoff value (this corresponds to $35 \mu \mathrm{g}$ of $\mathrm{Hgb} / \mathrm{g}$ of stool) and results are obtained within 21 days after returning the sample.

A group of patients not prescreened with FIT was included to evaluate quality markers which are potentially unbiased by the FIT risk stratification (negative: lower risk, positive: higher risk).

To ensure accuracy and maximize the likelihood that patients with presumed false-positive FIT tests truly lacked adenomas (and presented later to other doctors or the emergency department), the charts of these cases were reviewed for a second time after the completion of the analysis. However, no additional gastrointestinal problems were recorded (median 12 months, range 4.5-19 months for all 18 cases). True-negative FIT cases were also similarly reevaluated (median 8 months, range 1-20 months for 64 cases). Although a number of other problems were noted, no patient was discovered to develop new clinical gastrointestinal neoplasm. There were no chart notes after the recorded colonoscopy for 24 cases.

\section{Statistical analysis}

The cohort was divided into non-prescreened (FIT-not done [nd]) and prescreened (FIT-done) groups. The latter was also divided into FIT-positive (FIT+) and -negative (FIT-) groups. Descriptive statistics such as mean ( \pm standard deviation) and proportions were used to describe the cohort. Among the colonoscopy findings, two outcomes were of interest: advanced ADR and overall ADR (including the spectrum of adenomatous neoplasms).

The main analyses included the comparison of these two outcomes between FIT+ and FIT-groups in both univariate and multiple variable analyses. Adjusting factors included age, gender, previous adenomas or invasive cancer, family history, and presence of any symptoms (including bleeding, iron deficiency, abdominal pain, alteration in bowel habit, and weight loss). In secondary analyses, these two outcomes were studied among all patients (FIT-done and FIT-nd) using multiple variable analyses. The objective was to identify factors that are related to these two outcomes; the factors include the above-mentioned adjusting factors plus the variable that indicates whether FIT test was done or not. Odds ratios (ORs) and $95 \%$ CIs were provided. Statistical significance was accepted at $p \leq 0.05$. Finally, diagnostic accuracy of FIT test for identifying advanced adenomas was calculated among the patients who had undergone FIT test.

All analyses were performed using the SAS statistical analysis package, version 9.3 (SAS Institute Inc., Cary, NC, USA).

\section{Results}

There were 389 elective or semi-urgent colonoscopies performed during the 21-month span of the study. A total of 64 cases were excluded. Figure 1 shows the flow of patients. Cases involving surveillance for inflammatory bowel disease (IBD) were excluded, as well as a number of other patients for the reasons listed. It is of interest that of the IBD cases, seven had positive FIT results. A positive FIT in IBD patients has been previously described. ${ }^{15}$ After exclusions, 325 cases remained for the analysis of polyps. Complications included one perforation after polypectomy and two significant bleeds requiring repeat colonoscopic intervention during this period.

\section{Demographics and overall outcome}

Demographic features of 325 patients are shown in Table 1. The mean age of males was 60.8 years (median 61 years, $25 \%$ of them were over 70 years), while the mean age of females was 61.1 years (median 63 years, $25 \%$ of them were over 68 years). There was no significant age difference between males and females.

Table 2 shows overall findings in the entire group. There were $103(31.7 \%)$ positive cases. Overall, TA, TVA, or TA with HGD or invasive carcinoma was detected in $86(26.5 \%)$ patients. Of these, seven (2.2\%) had HGD (two cases) or invasive carcinoma (five cases) and 13 (4.3\%) cases were advanced adenomas (including four TVAs). Twenty-one patients had multiple TAs ranging from 2-10 per patient. In addition, two inflammatory polyps, one small patch of Crohn's disease, and a $<1 \mathrm{~cm}$ nodule of a neuroendocrine tumor were found in FIT- negative group. One small patch of 


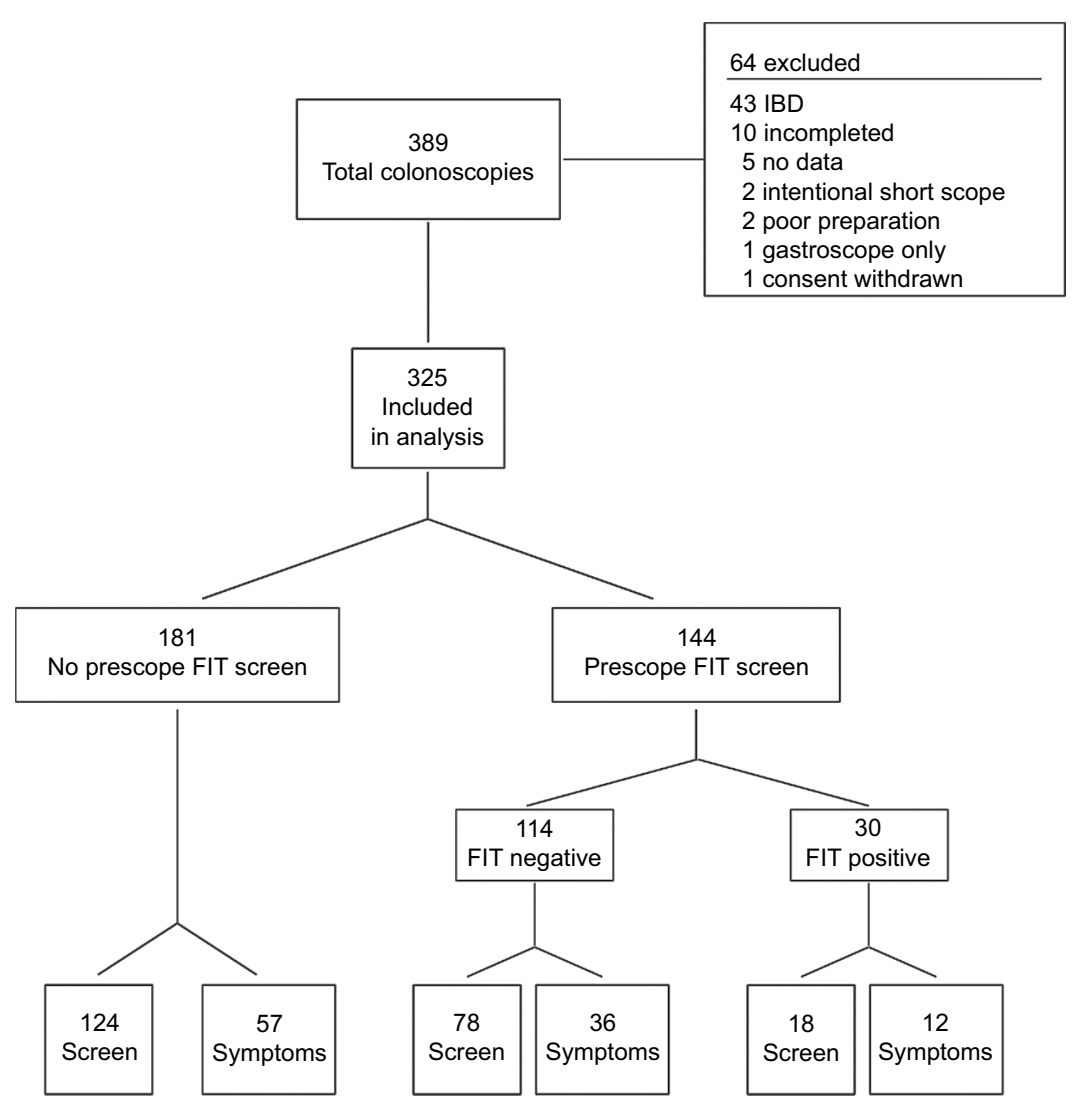

Figure I The total number of colonoscopies, included and excluded cases for a 21 -month period.

Notes: The indication "screen" includes all patients without any symptoms. This includes average risk, family history of adenomas or adenocarcinoma of the colorectum, previous finding of adenomas or colorectal cancer on previous colonoscopy as well as seven cases sent for colonoscopy because of positive FIT alone. The indication "symptoms" includes all symptoms including rectal bleeding, iron deficiency (with or without anemia), abdominal pain, change in bowel pattern, diarrhea (but not chronic constipation), or weight loss. Abbreviation: FIT, fecal immunochemistry test; IBD, inflammatory bowel disease.

Table I Demographic features of analyzed patients during the period under review

\begin{tabular}{|c|c|c|c|c|c|}
\hline Category & Total & FIT-not done & FIT-done & FIT negative & FIT positive \\
\hline Number of patients, $\mathrm{N}$ & 325 & 181 & 144 & 114 & 30 \\
\hline Mean age (years) $( \pm S D)$ & $60.9( \pm 12.1)$ & $60.8( \pm 11.9)$ & $61.0( \pm 12.5)$ & $60.1( \pm 12.1)$ & $64.3( \pm 13.5)$ \\
\hline Male gender & I7I (52.6) & $95(52.5)$ & $76(52.9)$ & $57(50)$ & $19(63.3)$ \\
\hline \multicolumn{6}{|c|}{ Withdrawal time in minutes $( \pm S D)$} \\
\hline - Including polyps & $6.0( \pm 4.6)$ & $5.3( \pm 3.5)$ & $6.9( \pm 5.6)$ & $7.0( \pm 5.9)$ & $6.4( \pm 3.7)$ \\
\hline - No polyps removed & $4.6( \pm 2.2)$ & $4.2( \pm I .7)$ & $5.0( \pm 2.6)$ & $5.1( \pm 2.8)$ & $4.5( \pm I .5)$ \\
\hline \multicolumn{6}{|l|}{ Preparation quality ( $\mathrm{N}=287$ ) } \\
\hline - Excellent & $207(72.1)$ & $121(68.8)$ & $86(77.5)$ & $66(81.5)$ & $20(66.7)$ \\
\hline- Good & $66(23.0)$ & $46(26.1)$ & $20(18.0)$ & $12(14.8)$ & $8(26.7)$ \\
\hline - Fair & $14(4.9)$ & $9(5.1)$ & $5(4.5)$ & $3(3.7)$ & $2(6.7)$ \\
\hline Positive FIT only ${ }^{\mathrm{a}}$ & 7 & - & 7 & - & 7 \\
\hline Screen (average risk) & $120(36.9)$ & $73(40.3)$ & $47(32.6)$ & $4 I(36.0)$ & $6(20.0)$ \\
\hline Family history ${ }^{\mathrm{a}}$ & $44(13.5)$ & $31(17.1)$ & $13(9.0)$ & $13(\mid \mathrm{I} .4)$ & 0 \\
\hline Prior polyp/colorectal cancer ${ }^{a}$ & $49(15.1)$ & $20(11.0)$ & $29(20.1)$ & $24(2 I . I)$ & $5(16.7)$ \\
\hline Any symptoms ${ }^{b}$ & $105(32.3)$ & $57(3 \mid .5)$ & $48(33.3)$ & $36(31.6)$ & $12(40.0)$ \\
\hline Abdominal pain & $31(9.5)$ & $16(8.8)$ & $15(10.4)$ & II (9.7) & $4(13.3)$ \\
\hline Rectal bleeding & $30(9.2)$ & $16(8.8)$ & $14(9.7)$ & $13(\mid \mathrm{I} .4)$ & I (3.3) \\
\hline Change in bowel pattern & $15(4.6)$ & $8(4.4)$ & $7(4.9)$ & $5(4.4)$ & $2(6.7)$ \\
\hline Weight loss & $4(1.2)$ & $4(1.2)$ & 0 & 0 & 0 \\
\hline Iron deficiency \pm anemia & $28(8.6)$ & $15(8.3)$ & $13(10.4)$ & $7(6.1)$ & $6(20.0)$ \\
\hline
\end{tabular}

Notes: aFor the purposes of this study, conventional risk factors were treated as screened patients. This includes seven patients colonoscoped for the presence of positive FIT alone. The main division in indications was presence or absence of symptoms; bsome symptoms overlap in the same patient, including rectal bleeding, iron deficiency, abdominal pain or diarrhea, weight loss, and change in bowel pattern. The percentages are based on available data for the entire group. The percent of the specific symptom is calculated based on the total number of patients. Data presented as $\mathrm{n}(\%)$ unless otherwise indicated.

Abbreviation: FIT, fecal immunochemistry test. 
Table 2 Summary of colonoscopy findings in all patients and in the different groups ${ }^{\mathrm{a}}$

\begin{tabular}{|c|c|c|c|c|c|c|c|}
\hline \multirow[t]{2}{*}{ Category } & \multirow[t]{2}{*}{ Total } & \multicolumn{3}{|c|}{ All patients, $\mathrm{N}=325$} & \multicolumn{3}{|c|}{ FIT-done patients, $N=I 44$} \\
\hline & & FIT-not done & FIT-done & $p$-value & FIT negative & FIT positive & p-value \\
\hline Number of patients & 325 & 181 & 144 & & 114 & 30 & \\
\hline Advanced adenomas or & $20(6.2)$ & $9(5.0)$ & II (7.6) & 0.3204 & $4(3.5)^{b}$ & $7(23.3)$ & 0.0016 \\
\hline invasive adenocarcinoma & & 2/9 TVA & & & I/4 TVA & I/7 TVA & \\
\hline Overall adenomas & $86(26.5)$ & $46(25.4)$ & $40(27.8)$ & 0.6314 & $28(24.5)$ & $12(40.0)$ & 0.0930 \\
\hline CA or TA HGD & $7(2.2)$ & $5(2.8)^{c}$ & $2(1.4)^{c}$ & & 0 & $2(6.7)^{c}$ & \\
\hline $\mathrm{TA}=2 \mathrm{~cm}$ or $\mathrm{I} \mathrm{cm}$ & $13(4.0)$ & $4(2.2)$ & $9(6.3)$ & & $4(3.5)$ & $5(16.7)$ & \\
\hline $\mathrm{TA}<\mathrm{lcm}$ & $66(20.0)$ & $37(20.1)$ & $29(20.1)$ & & $24(21.0)$ & $5(16.7)$ & \\
\hline HP & $7(2.2)$ & $7(3.9)$ & 0 & & 0 & 0 & \\
\hline SSA & $4(0.9)$ & $4(2.2)$ & 0 & & 0 & 0 & \\
\hline
\end{tabular}

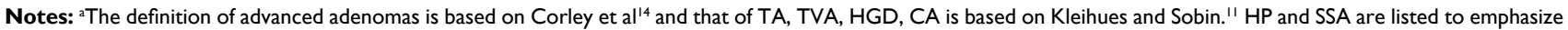
that these are not part of the definition of adenoma detection rate reference. ${ }^{12}$ there were no cases of adenoma with HDG or invasive CA in FIT-negative group. ${ }^{\mathrm{C}}$ There were three invasive adenocarcinomas and two adenomas with HDG in FIT-not done group. Both were invasive CAs in FIT-done (Fit+) group. Data presented as n (\%).

Abbreviation: CA, invasive adenocarcinoma; FIT, fecal immunochemistry test; HGD, high-grade dysplasia; HP, hyperplastic polyps; SSA, sessile serrated adenomas (SSA); TA, tubular adenoma; TVA, tubulovillous adenoma.

Crohn's disease was found in the FIT+ group and one case of collagenous colitis was found in a patient in the FIT-nd group.

The comparison of total adenoma distributions between FIT+ and FIT - groups were similar. In the FIT+ group, there were four advanced adenomas: two adenomas $<1 \mathrm{~cm}$ in the descending colon, a Dukes' A invasive adenocarcinoma in the descending colon, and a distal transverse invasive cancer (Dukes' C). There were also four tubular adenomas in the ascending colon of which one was advanced.

In the FIT-group, there were no adenomas with HGD and no invasive cancers. The distribution was 18 in the descending colon (one advanced), four in the transverse colon (two advanced), and six in the ascending colon (two advanced). In this FIT- group, three patients had 5-10 polyps each, all less than $1 \mathrm{~cm}$.

\section{Quality of colonoscopy}

Cecal intubation was achieved in over $95 \%$ of patients. The quality of preparation was excellent in almost three-quarters of the patients, and in the rest good visualization was possible in most of them. The withdrawal time was somewhat shorter than recommended. ${ }^{16}$ Based on the current definition of ADR for average-risk patients, which excludes hyperplastic polyps and serrated adenomas, ${ }^{13}$ this was 17/73 (23.3\%, combined for males and females) in the non-prescreened group.

\section{Statistical results}

Comparison of the overall ADR between FIT-nd and FIT-done groups showed no significant difference $(25.4 \%$ vs $27.8 \%$; $p=0.6314)$. Also, comparison between advanced adenomas and invasive cancer did not show a significant difference between the FIT-done and FIT-nd groups (5.0\% vs 7.6\%, $p=0.32$ ). Comparison of the ADR between FIT+ and FITgroups did show a large difference (40\% vs $24.5 \%$ ), but this did not reach statistical significance $(p=0.093)$. However, comparison for detection of advanced adenomas and adenocarcinoma between FIT+ and FIT-groups did show statistical significance: $23.3 \%$ vs $3.5 \%, p=0.0016$ (Table 2 ).

Other univariate analyses were carried out (data not shown). Male gender and age were significantly associated with greater adenoma detection rate independent of the type of adenomas in either groups of Fit-done or -not done.

Table 3 shows results from multiple variable analyses. Out of the five potential independent factors mentioned in the "Statistical analyses" section (different symptoms are combined into one dichotomous variable indicating existence of any symptom), only gender showed significant association with both outcomes and in both patient groups (all patients or FIT-done patients): Male patients had significantly more overall ADR and advanced neoplasm detection rates than female patients. Comparing overall ADRs between FIT+ and FIT- groups while adjusting for gender effect showed an OR $=1.8$ (95\% CI: $0.7-4.4$, not statistically significant), while comparing for detection of

Table 3 Results from multiple variable analyses

\begin{tabular}{lll}
\hline FIT-done patients & $\begin{array}{l}\text { Odds ratio for } \\
\text { all polyps }\end{array}$ & $\begin{array}{l}\text { Odds ratio for } \\
\text { advanced polyps }\end{array}$ \\
\hline Fit+ & I.8 $(0.7-4.4)$ & $\begin{array}{l}7.6(2.0-29.3) \\
\text { reference }\end{array}$ \\
Fit- & reference & 9.1 (I.I-76.9) \\
Male & $4.3(1.9-10.1)$ & reference \\
Female & reference & \\
All patients & $2.5(1.5-4.2)$ & $3.9(1.3-I 1.9)$ \\
Male & reference & reference \\
\hline
\end{tabular}

Notes: Statistical significance was achieved with FIT for advanced adenomas and male gender was associated with both advanced and all adenomas. These are marked in bold.

Abbreviation: FIT, fecal immunochemistry test. 
advanced neoplasms, OR =7.6 (95\% CI: 2.0-29.3), which is highly significant.

In this study, the sensitivity and specificity of the FIT test was $30 \%$ and $82.7 \%$, respectively, for overall ADR and was $63.6 \%$ and $82.7 \%$, respectively, for advanced neoplasms. Positive and negative predictive values were $40 \%$ and $75.4 \%$, respectively, for overall ADR and $23.3 \%$ and $96.5 \%$, respectively, for advanced neoplasms.

\section{Discussion}

In this study, we observed that a one-time FIT prior to colonoscopy indicates greater chance of detecting advanced adenomas or invasive adenocarcinoma. A positive FIT increased ADR for all adenomas, although this was not statistically significant. The FIT was moderately sensitive and specific in predicting presence of advanced colonic neoplasms. A negative FIT, however, had a high likelihood of eliminating advanced colonic neoplasms. Nevertheless, some advanced adenomas and several cases of multiple adenomas were missed by the FIT. Males were confirmed to have a higher likelihood of developing adenomas.

Screening for CRC has now shown benefit for reducing mortality from this common disease. ${ }^{2-4}$ For over three decades, the gold standard for detecting adenomas and adenocarcinoma relied on mass colonoscopy. However, the costs are prohibitive, if there are limited funds available. ${ }^{17,18}$ Therefore, alternative cheaper, yet, reliable methods are sought to limit colonoscopies. The performance of the FIT may be able to achieve this goal. ${ }^{19}$ FIT-based programs have been initiated in a number of countries. ${ }^{17-20}$ While significant progress has been made in identifying advanced adenomas, interval cancers still appear to be relatively high in stoolbased tests. ${ }^{21,22}$ Our province of Quebec, Canada, may be heading toward a similar FIT-based screening program. Therefore, the adjunctive role of fecal testing in a variety of different indications is relevant.

An important caveat for screening and proper adjunctive use of FIT is that the quality of examinations meet the standards. The ADR is one such important parameter $(>15 \%$ in females and $>25 \%$ in males). Although the ADR in this study is somewhat less than the preferred standards, it is similar to some of the previously published rates from different gastroenterology practices. ${ }^{23,24}$

The FIT, based on an antibody against the globin part of human blood, is independent of diet or oxidation. The FIT is more sensitive and specific to lower gastrointestinal bleeding because globin is degraded by proteases along the intestine. ${ }^{25}$ There is no significant difference in detecting neoplasms from proximal or distal colon, ${ }^{26}$ and a single test is qualitatively similar to multiple tests. ${ }^{6,25}$ The FIT is less able to detect pre-malignant serrated adenomas..$^{27,28}$ Other tests, such as the fecal DNA test, ${ }^{27}$ compares favorably with FIT in detecting serrated adenomas, possibly because these are less likely to bleed ${ }^{29}$ and more difficult to detect on colonoscopy. ${ }^{30}$ However, SSAs were not part of the ADR definition.

FIT characteristics should be optimal to detect the most number of adenomas but performance varies with different kits. Reporting of results is not yet standardized, although there is a plea to report values as micrograms of $\mathrm{Hgb}$ instead of $\mathrm{ng} / \mathrm{mL}$ of buffer. ${ }^{31}$

Sensitivity and specificity of the FIT in this study were lower, particularly for advanced neoplasms, than those found in a meta-analysis of controlled trials. ${ }^{6}$ The reason(s) for this are not clear but could be due to the heterogeneous population and small sample size included in this study. Another possibility could relate to the high cutoff level used in the current kit. In a number of earlier studies, a low Hgb cutoff level was associated with higher sensitivity, but lower specificity. ${ }^{4,5,32}$ According to the manufacturer's instructions, the cutoff level used was $175 \mathrm{ng} / \mathrm{mL}$ of buffer $(35 \mu \mathrm{g} / \mathrm{g}$ of stool), which is higher than $100 \mathrm{ng} / \mathrm{mL}(20 \mu \mathrm{g} / \mathrm{g}$ of stool) reported in other publications. ${ }^{4}$ However, some cancers may not bleed, and therefore can be missed even with lower Hgb cutoff values. ${ }^{22}$ Nevertheless, the cost of screening diminishes due to the need for fewer colonoscopies.

A number of features that are currently used to assess risks were also included. Among these, age and gender were significantly associated with ADR, but gender differences were the most consistent with or without FIT tests. The increased rates of adenomatous polyps in males, independent of age, compared with females has been previously noted. ${ }^{33,34}$

Other clinical variables associated with increased risk such as rectal bleeding, iron deficiency anemia, and altered bowel movements were less clearly associated in this study. ${ }^{35}$ Iron deficiency showed a significant effect in the FIT+ group with advanced neoplasms. When included in the multiple variable models, iron deficiency still showed statistical significance with outcome for advanced adenomas and cancer. However, other variables included in the model remained unchanged (i.e., FIT+/FIT - and/or gender); relatively slight changes occurred in the OR of results between FIT+ and FIT-groups. Because the iron deficiency variable was based both on history and laboratory values, we decided not to adjust for iron deficiency in our final analyses. While a set of symptoms do have value in predicting $\mathrm{CRC},{ }^{36}$ the presence of rectal bleeding only is less valuable as a marker. ${ }^{37}$ 
Several weaknesses need to be addressed. First, the sample size is quite small, and there are few positive FIT outcomes. As a result, the failure to associate higher ORs with established risk factors is blunted. Second, the population is heterogeneous, which also limits assessment of these risk factors. ${ }^{8,38,39}$ Third, the cohort is based mostly on clinical experience at a single university, possibly limiting generalizability. However, the singular prominence of FIT findings suggests that the test could perform reasonably well in patients with different risk factors. Confirmation of the effect of gender, despite small size, supports this notion.

In conclusion, this limited study provides insight into the possible use of FIT pre-colonoscopy for different indications. The main advantage appears to be detection of advanced neoplasms. Although it may increase the ADR, this study was underpowered to achieve statistical significance. This latter feature may be important to enhance quality of colonoscopy. Further clinical trials will be needed to establish whether the FIT or other stool tests could replace current risk-dependent colonoscopy or surveillance guidelines.

\section{Acknowledgment}

The authors would like to thank Wendi G Kotler for accumulating data on colonoscopies and additional tests.

\section{Disclosure}

The authors report no conflicts of interest in this work.

\section{References}

1. Torre LA, Bray F, Siegel RL, et al. Global cancer statistics, 2012. CA Cancer J Clin. 2015;65(2): 87-108.

2. Hewitson P, Glasziou P, Watsin E, Towler B, Irwig L. Cochrane systematic review of colorectal cancer screening using the fecal occult blood test (hemocult): an update. Am J Gastroenterol. 2008;103(6): 1541-1549.

3. Piper MA, Perdue LA, et al. Screening for colorectal cancer: updated evidence report and systematic review for the US preventive services task force. JAMA. 2016;315(5):2576-2594.

4. Inadomi JM. Screening for colorectal neoplasia. NEnglJMed. 2017;376(6): $149-156$

5. Levi Z, Rozen P, Hazazi R, et al. Quantitative immunochemical fecal occult blood test for colorectal neoplasia. Ann Intern Med. 2007;146(4): 244-255.

6. Lee JK, Liles EG, Bent S, Levin TR, Corley DA. Accuracy of fecal immunochemical tests for colorectal cancer: systematic review and meta-analysis. Ann Intern Med. 2014;160(3):171-181.

7. Lieberman DA, Rex DK, Winawer SJ, Giardiello FM, Johnson DA, Levin TR; United States Multi-Society Task Force on Colorectal Cancer. Guidelines for colonoscopy surveillance after screening and polypectomy: a consensus update by the US Multi-Society Task Force on Colorectal Cancer. Gastroenterology. 2012;143(3):844-857.

8. Samadder NJ, Curtin K. The impact of family history on the risk of colorectal neoplasia and screening practices. Clin Gastroenterol Hepatol. 2017;15(8):1204-1206.
9. Parmar R, Martel M, Rostom A, Barkun AN. Validated scales for colon cleansing: a systematic review. Am J Gastroenterol. 2016;111(2): 197-204

10. GIHEP. Aronchick Bowel Preparation Scale (modified). Available from: http://gihep.com/calculators/aronchick/. Accessed September 17, 2017.

11. Kleihues P, Sobin LH, editors. World Health Organization Classification of Tumours. Lyons: IARC Press; 2000:103.

12. Lieberman DA, Prindiville S, Weiss DG, Willett W; VA Cooperative Study Group 380. Risk factors for advanced colonic neoplasia and hyperplastic polyps in asymptomatic individuals. JAMA. 2003;290(22):2959-2967.

13. Gupta N. How to improve your adenoma detection rate. Gastroenterology. 2016;151(6):1054-1057.

14. Corley DA, Jensen CD, Marks AR, et al. Adenoma detection rate and risk of colorectal cancer and death. $N$ Engl J Med. 2014;370(14): 1298-306.

15. Kato J, Hiraoka S, Nakarai A, Takashima S, Inokuchi T, Ichinose M. Fecal immunochemical test as a biomarker for inflammatory bowel diseases: can it rival fecal calprotectin? Intest Res. 2016;14(1):5-14.

16. Kumar S, Thosani N, Ladabaum U, et al. Adenoma miss rates associated with a 3-minute versus 6-minute colonoscopy withdrawal time: a prospective, randomized trial. Gastrointest Endosc. 2017;85(6):1273-1280.

17. WilschutJA, Habbema JD, van Leerdam ME, etal. Fecal occult blood testing when colonoscopy capacity is limited. J Natl Cancer Inst. 2011;103(23): 1741-1751.

18. Wilschut JA, Hol L, Dekker E, et al. Cost-effectiveness analysis of a quantitative immunochemical test for colorectal cancer screening. Gastroenterology. 2011;141(5):1648-1655.

19. Crotta S, Segnan N, Paganin S, Dagnes B, Rosset R, Senore C. High rate of advanced adenoma detection in 4 rounds of colorectal cancer screening with the fecal immunochemical test. Clin Gastroenterol Hepatol. 2012;10(6):633-638.

20. Digby J, Fraser CG, Carey FA, Diament RH, Balsitis M, Steele RJ. Faecal haemoglobin concentration is related to detection of advanced colorectal neoplasia in the next screening round. J Med Screen. 2017;24(2): $62-68$.

21. van der Vlugt M, Grobbee EJ, Bossuyt PMM, et al. Interval colorectal cancer incidence among subjects undergoing multiple rounds of fecal immunochemical testing. Gastroenterology. 2017;153(2): 439-447.

22. Digby J, Fraser CG, Carey FA, Lang J, Stanners G, Steele RJ. Interval cancers using a quantitative faecal immunochemical test (FIT) for haemoglobin when colonoscopy capacity is limited. J Med Screen. 2016;23(3):130-134.

23. Inra JA, Nayor J, Rosenblatt M, et al. Comparison of colonoscopy quality measures across various practice settings and the impact of performance scorecards. Dig Dis Sci. 2016;62(4):1-9.

24. Melson J, Berger D Greenspan M, Bayoumi M, Jakate S. Maintaining low non-neoplastic polypectomy rates in high-quality screening colonoscopy. Gastrointest Endosc. 2017;85(3):581-587.

25. Allison JE, Fraser CG, Halloran SP, Young GP. Population screening for colorectal cancer means getting FIT: the past, present, and future of colorectal cancer screening using the fecal immunochemical test for hemoglobin (FIT). Gut Liver. 2014;8(2):117-130.

26. de Wijkerslooth TR, Stoop EM, Bossuyt PM, et al. Immunochemical fecal occult blood testing is equally sensitive for proximal and distal advanced neoplasia. Am J Gastroenterol. 2012;107:1570-1578.

27. Imperiale TF, Ransohoff DF, Itzkowitz SH, et al. Multitarget stool DNA testing for colorectal cancer screening. N Engl J Med. 2014;370: 1287-1297.

28. East JE, Atkin WS, Bateman AC, et al. British Society of Gastroenterology position statement on serrated polyps in the colon and rectum. Gut. 2017;66(7):1181-1196.

29. Waldock A, Ellis IO, Armitage NC, Turner DR, Hardcastle JD. Histopathological assessment of bleeding from polyps of the colon and rectum. J Clin Pathol. 1989;42:378-382. 
30. Rex DK, Ahnen DJ, Baron JA, et al. Serrated lesions of the colorectum: review and recommendations from an expert panel. Am J Gastroenterol. 2012;107:1315-1329.

31. Fraser CG, Allison JE, Halloran SP, et al. A proposal to standardize reporting units for fecal immunochemical tests for hemoglobin. J Natl Cancer Inst. 2012;104(11):810-814.

32. Terhaar sive Droste JS, Oort FA, van der Hulst RW, et al. Higher fecal immunochemical test cutoff levels: lower positivity rates but still acceptable detection rates for early-stage colorectal cancers. Cancer Epidemiol Biomarkers Prev. 2011;20:272-280.

33. Corley DA, Jensen CD, Marks AR, et al. Variation of adenoma prevalence by age, sex, race, and colon location in a large population: implications for screening and quality programs. Clin Gastroenterol Hepatol. 2013;11(2):172-180.

34. McCashland TM, Brand R, Lyden E, de Garmo P; CORI Research Project. Gender differences in colorectal polyps and tumors. Am J Gastroenterol. 2001;96(3):882-886.
35. Rasool S, Kadla SA, Rasool V, Ganai BA. A comparative overview of general risk factors associated with the incidence of colorectal cancer. Tumour Biol. 2013;34(5):2469-2476.

36. Hamilton W, Round A, Sharp D, Peters TJ. Clinical features of colorectal cancer before diagnosis: a population-based case-control study. $\mathrm{Br} J$ Cancer. 2005; 93(4):399-405.

37. Robertson R, Mant D, Primrose J, Nugent MA, Macleod U, Sherma R. Predicting colorectal cancer risk in patients with rectal bleeding. $\mathrm{Br} J$ Gen Pract. 2006;56(531):763-767.

38. Forsberg AM, Hagel E, Jaramillo E, Rubio CA, Björck E, Lindblom A. Predicting outcome in colonoscopic high-risk surveillance. Anticancer Res. 2015;35(9):4813-4819.

39. Goede SL, Rabeneck L, Lansdorp-Vogelaar I, et al. The impact of stratifying by family history in colorectal cancer screening programs. Int J Cancer. 2015;137(5):1119-1127.
Clinical and Experimental Gastroenterology

\section{Publish your work in this journal}

Clinical and Experimental Gastroenterology is an international, peerreviewed, open access, online journal publishing original research, reports, editorials, reviews and commentaries on all aspects of gastroenterology in the clinic and laboratory. This journal is included on PubMed. The manuscript management system is completely online

\section{Dovepress}

and includes a very quick and fair peer-review system, which is all easy to use. Visit http://www.dovepress.com/testimonials.php to read real quotes from published authors. 